\title{
O ENSINO DOS SISTEMAS DEFENSIVOS DO HANDEBOL: CONSIDERAÇÕES METODOLÓGICAS ACERCA DA CATEGORIA CADETE
}

\author{
Rafael Pombo Menezes \\ Universidade Estadual de Campinas, Campinas, São Paulo, Brasil
}

\begin{abstract}
Resumo
$\mathrm{Na}$ categoria cadete, o ensino dos sistemas defensivos deve priorizar a resolução dos mais variados tipos de tarefas, sejam elas motoras ou cognitivas, considerando os níveis de desenvolvimento dos jogadores, os métodos de ensino adotados pelos treinadores e as experiências prévias dos jogadores dentro da modalidade. A identificação dessas características permite apontar a necessidade da formação de defensores ofensivos, que perturbem constantemente os atacantes adversários, limitando suas áreas de atuação e dificultando o jogo coletivo ofensivo, para que haja a rápida recuperação da posse de bola. O trabalho do treinador deve pautar-se na formação de jogadores com atuação plural e de comportamento flexível no jogo, e não de jogadores especializados técnico-taticamente.
\end{abstract}

Palavras-chave: Handebol - Pedagogia do Esporte - Tática Defensiva

\section{Introdução}

$\mathrm{O}$ handebol, assim como as demais modalidades coletivas, é composto por diferentes aspectos: o técnico, o tático, o da preparação física, o da preparação psicológica, entre outros. Tais componentes estão relacionados diretamente com as fases do jogo, ofensiva, defensiva e transições, as quais estão inter-relacionadas (BAYER, 1994), possuem objetivos e, consequentemente, exigem diferentes sistemas de resolução de tarefas. Podemos caracterizá-lo como uma modalidade de oposição, na qual duas equipes disputam entre si um vencedor de acordo com seu regulamento; de invasão, em que uma equipe pode apropriar-se do terreno de jogo adversário, na tentativa de anotar seus pontos; e de cooperação, relacionada com a necessidade de colaboração mútua entre os jogadores de uma equipe, constituindo posterior- 
mente as táticas grupais e coletivas.

De acordo com as suas características, o handebol pode ser classificado como um Jogo Coletivo Esportivizado (ou JCE) (REIS, 1994), com ações simultâneas de atacantes e defensores, em regiões próximas ou distantes da qual a bola está localizada. Esse é regido por estratégias e táticas, sendo elas individuais e coletivas, ofensivas, defensivas e de transição, que dependem, sobretudo, da percepção dos jogadores sobre as situações que o jogo impõe e da tomada de decisão dos jogadores que respeite as regras da modalidade e que objetive a resolução de tarefas.

Os sistemas de resolução de tarefas, especificamente para os atacantes, envolvem o controle da bola, os deslocamentos com e sem a posse da bola, a execução dos fundamentos - empunhadura, passe, recepção, arremesso, drible, ritmo trifásico e duplo ritmo trifásico - inseridos em um contexto tático do jogo, como em situações de superioridade $(3 \times 2,2 \times 1 \ldots)$, igualdade $(1 \times 1,2 \times 2 \ldots)$ ou inferioridade numérica $(1 \times 2,2 \times 3 \ldots)$. No caso dos defensores, a primeira diferença consiste no fato de não possuírem a bola, que implica na prioridade de defender a meta, não deixando a bola e os adversários aproximarem-se dela, dispondo também de técnicas e táticas individuais e coletivas.

Nesta pesquisa, a tática será considerada como uma dimensão de prazo mais curto que a estratégia (relacionada à coordenação e à organização do conjunto das táticas ofensiva, defensiva e de transição), como o conjunto de ações individuais a serem tomadas, inteligentemente, pelos membros da equipe para atingir os objetivos coletivos propostos para tal situação, seja de ataque, de defesa ou de transição. A tática também engloba a execução dos meios táticos ofensivos e defensivos para gerar situações favoráveis aos referidos sistemas. Segundo Moreira e Tavares (2004), o sistema de jogo é a forma na qual os jogadores se distribuem na quadra durante o jogo sendo uma estrutura indispensável da tática coletiva.

Segundo Herrero (2003), defender, no handebol, implica não somente na resolução de tarefas motoras, mas também de tarefas cognitivas. Significa que, desde a iniciação esportiva até o alto nível de rendimento, os defensores devem ser submetidos a todos os instantes, nas aulas ou treinos, à resolução de tarefas, sejam essas simples ou complexas, de caráter individual, grupal ou coletivo (GRECO, 1998).

A inserção dos defensores em um contexto tático é caracterizada por alguns dos níveis de relação apontados por Garganta (1995), den- 
tre os quais estão descritas as interações entre os jogadores - companheiros e adversários - bola e alvo. Dentro do contexto defensivo, muitas vezes com certa restrição de espaço que se limita às zonas mais próximas da bola, todas as ações dos defensores devem ser conduzidas individualmente, como as maneiras de pensar e analisar as situações do jogo (SIMÕES, 2002), e coletivamente, de forma a intervir inteligentemente na busca pela recuperação da posse da bola. Tais intervenções devem enfatizar as tentativas de roubada da bola (por aproximação em relação ao atacante), a interceptação dos passes (quando o defensor interpõe-se à linha de passe), ou mesmo a priorização de arremessos das zonas mais próximas às laterais da quadra (de onde os goleiros podem ter uma facilitação em sua intervenção, devido ao maior grau de dificuldade para os atacantes).

Defender, no handebol e em outras modalidades coletivas, sugere implicações não apenas táticas quando nos remetemos ao contexto do jogo, mas também relacionadas às questões psicológicas. Quando uma equipe passa pela fase defensiva obtendo êxito, a consequência é percebida em uma maior tranquilidade durante a fase ofensiva subsequente. Essa condição pode ser verificada com maior frequência nos períodos finais de partidas que se apresentam empatadas.

Uma das maiores dificuldades enfrentadas pelos treinadores consiste no fato de que os jogadores buscam cada vez mais tardiamente a prática do handebol, o que resulta em grupos heterogêneos. Segundo Ré et al. (2005), é comum, em uma equipe competitiva ou em um mesmo grupo de treinamento, encontrarmos jovens de diferentes estágios maturacionais. Tal situação "pode favorecer os mais adiantados no processo de desenvolvimento biológico, e pode desmotivar outros mais tardios" (RÉ et al. 2005, p. 153).

Essa dificuldade pode ser decorrente de fatores como: a) a não inserção do handebol em algumas escolas como possibilidade de conteúdo, como o mini-handebol para as crianças ou mesmo variantes do jogo para os adolescentes; b) a rara veiculação em canais abertos de televisão de partidas das Seleções Nacionais ou de competições nacionais; e c) mesmo a falta de conhecimento, por parte de alguns professores, das regras e do funcionamento da dinâmica da modalidade. É comum depararmo-nos com clubes ou municípios que iniciam suas equipes na categoria cadete (15-16 anos) ou mesmo juvenil (17-18 anos).

O objetivo desta pesquisa é identificar as características dos joga- 
dores quando estão na categoria cadete e fornecer indicativos para que haja um possível balizamento das condutas defensivas durante esta fase do ensino. Para isso, o principal problema a ser discutido nesta pesquisa é a forma com que o ensino dos sistemas defensivos é conduzido até e na categoria cadete.

\section{O ensino dos sistemas defensivos}

Uma grande dificuldade no ensino dos sistemas defensivos fundase em transmitir o significado e a importância de "defender" para as crianças e adolescentes. Claramente quando a maioria procura a prática do handebol, assim como ocorre no futebol, a principal motivação está na possibilidade de marcar gols, sendo que no handebol há maior facilidade quando pensarmos que, com as mãos, temos melhor controle e domínio da bola que com os pés.

Os sistemas defensivos são instituídos com o objetivo de propiciar uma organização coletiva para as ações defensivas, por vezes delimitando as áreas de atuação dos jogadores ou apontando os adversários a serem marcados. Para isso, são necessários o entendimento da dinâmica de funcionamento do sistema e o motivo de seu posicionamento ou atitudes a serem tomadas.

Ao aprofundarmo-nos na literatura que aborda os aspectos pedagógicos do ensino dos sistemas defensivos no handebol, percebemos que há um pensamento convergente quanto ao primeiro sistema a ser ensinado. Para Antón (1990) e Ehret et al. (2002), o primeiro sistema defensivo a ser ensinado ainda nas categorias mirim (11-12 anos) e infantil (13-14 anos) é o individual, primeiramente em suas variações em quadra inteira e meia-quadra, para que posteriormente sejam introduzidos os sistemas zonais.

No Brasil, como consequência de produções literárias como as supracitadas e de capacitações oferecidas pela Confederação Brasileira de Handebol ( $\mathrm{CBHb})$, nas categorias mirim e infantil é consenso, e inclusive parte do regulamento de algumas competições, que sejam adotadas as marcações individual - em quadra inteira, em meia-quadra ou por aproximação - ou em duas linhas defensivas. Na categoria cadete, as restrições quanto aos sistemas defensivos incluem, em alguns casos, a utilização de sistemas defensivos mistos ou combinados (zonal + individual).

As implicações na aplicação de defesas individuais ou abertas, nas 
categorias infantil e cadete, fundam-se nas premissas técnico-táticas e da preparação física. Do ponto de vista da preparação física, o jogo torna-se mais veloz e, consequentemente, com intensidades maiores, principalmente pela necessidade de acompanhamento do atacante direto durante toda a partida. Em relação aos aspectos técnico-táticos, alguns objetivos das categorias mais jovens (mirim e infantil) permanecem presentes, como o constante pressionamento dos atacantes, que propicia para esses o desenvolvimento de táticas individuais como a finta e o desmarque, e a marcação direta na tentativa de recuperação da posse de bola, seja durante o drible do atacante ou na tentativa de interceptação de um passe, que auxiliarão na construção e estruturação, mental e prática, dos sistemas defensivos zonais.

O sistema individual deve buscar desenvolver nos jogadores algumas características que serão de fundamental relevância ao ensino dos sistemas defensivos zonais. Algumas considerações pertinentes são:

- Cada defensor possui a sua responsabilidade, ou seja, cada defensor é responsável pelo seu oponente direto, esteja ele com ou sem a posse da bola;

- O defensor deverá posicionar-se entre o atacante e o gol, em uma relação de proximidade, dificultando as ações desse atacante e mesmo dificultando a relação ofensiva de passe e recepção;

- O desenvolvimento da noção espacial do defensor, dada pelos deslocamentos dos atacantes, e seu constante acompanhamento pelos defensores, na quadra de jogo, impedindo com que haja uma aproximação dos atacantes em relação à sua meta. Ou seja, o defensor translada-se de um lugar para outro de forma a responder à situação do atacante (MEDINA; ORTÍN, 2002);

- O desenvolvimento de uma estratégia de relação com seu oponente que dificulte suas ações, a partir da contextualização de suas ações.

Os sistemas defensivos abertos, em decorrência do aprendizado proporcionado pelo ensino da defesa individual nas categorias menores, devem ser os pilares do jogo na categoria cadete. Entende-se por sistemas defensivos abertos aqueles nos quais os jogadores são dispostos em duas ou mais linhas, como o 1:5, o 3:3, o 3:2:1, o 4:2 e o 5:1. Em decorrência dessas fases anteriores de aprendizagem, em que o principal conceito é o de manter os sistemas defensivos o mais ofensivos possível, o ímpeto inicial de ofensividade defensiva na categoria cadete não deve ser desencorajado. A premissa de perturbar constantemente os atacantes tem objetivos interessantes do ponto de vista defensivo, como a limitação das áreas ofensivas e a rápida 
combatividade, originários da dificultação do jogo coletivo ofensivo.

O comportamento do defensor deve ser entendido como um processo de longo prazo, e esse processo deverá propiciar conhecimentos e formas de atuação flexíveis a ele, fundamentando-se na necessidade de adaptação às constantes mudanças impostas pelos atacantes e por suas interações. Nesta perspectiva, o defensor deve ser apto a captar informações dos adversários de forma que consiga antecipar-se a prováveis tomadas de decisão não apenas de seu marcador direto, como também dos demais atacantes para buscar ajudas mútuas e coberturas.

Surge a necessidade, então, de provocar o maior número de variações possível também nas situações ofensivas durante as sessões de treinamentos ou aulas, com o objetivo de ampliar o repertório de respostas táticas defensivas, seja em superioridade, igualdade ou inferioridade numérica. Ainda assim, é de suma importância que todos os jogadores vivenciem todos os postos específicos defensivos, não apenas para saber desempenhar as funções táticas em cada um deles, mas também para compartilhar as dificuldades e possibilidades de intervenção em cada posto.

Baseado nos conceitos de Ehret et al. (2002) e de Antón (1990), que sugerem que as defesas, na fase de formação do jogador, devem apresentar uma postura ofensiva, entendemos que, em contrapartida, os defensores devem saber jogar de diferentes formas, como adotando posturas mais defensivas ou mesmo antecipativas. Essa variabilidade no comportamento tático defensivo sugere uma grande variação de estímulos aos defensores, primeiramente para que se aprenda a jogar de diferentes formas e também para que o defensor, ao observar seu marcador direto durante o jogo, possa selecionar ou alterar sua forma de marcar, tendo como principal objetivo a troca da referência que seu marcador possui da relação de oposição direta $(1 \mathrm{x} 1)$.

Um dos grandes conteúdos que devem ter uma ênfase especial, desde a iniciação no handebol até o alto nível, se refere à capacidade de locomoção dos jogadores. Em especial nas situações defensivas os jogadores devem dominar todos os tipos de deslocamentos: para frente, para trás, em diagonais e laterais; sejam esses deslocamentos em alta, média ou baixa velocidade, e de forma a manter sempre a postura de "alerta" defensivo. A importância da capacidade de boa locomoção dos defensores pode ser refletida em ações como:

- Realizar bloqueios defensivos, individualmente ou em grupos, para evitar que a bola chegue ao gol; 
- Trocar de marcação diante de bloqueios ofensivos (pela realização de contra-bloqueios), para evitar que a bola seja passada para o pivô ou que haja infiltração de um dos armadores;

- Avançar rapidamente na direção de um atacante que quica a bola (dribla), ou mesmo acompanhá-lo durante uma ação contínua de drible, para roubar a bola ou dificultar a progressão do jogador;

- Realizar os movimentos de báscula (ou deslizamento) na direção em que ocorre a circulação da bola, com o objetivo de gerar superioridade numérica defensiva na região próxima à da bola;

- Encobrir espaços aparentemente existentes (ou "vazios defensivos") nos quais os atacantes tenham a possibilidade de infiltração e arremesso;

- Recuperar rapidamente a bola de rebotes provenientes do goleiro ou das traves para iniciação rápida da fase de contra-ataque.

O funcionamento dos sistemas defensivos também depende diretamente do bom desenvolvimento do jogo ofensivo pela relação de oposição direta e, ao mesmo tempo, está vinculado aos processos ofensivos descritos por Bayer (1994) que são: a manutenção da posse de bola, a progressão em direção à meta adversária e a marcação do gol. O desenvolvimento da capacidade de locomoção dos defensores, como descritos anteriormente, visa atingir os três princípios defensivos propostos pelo autor supracitado a partir de ações que vão de encontro aos princípios ofensivos, conforme indicado na Figura 1.

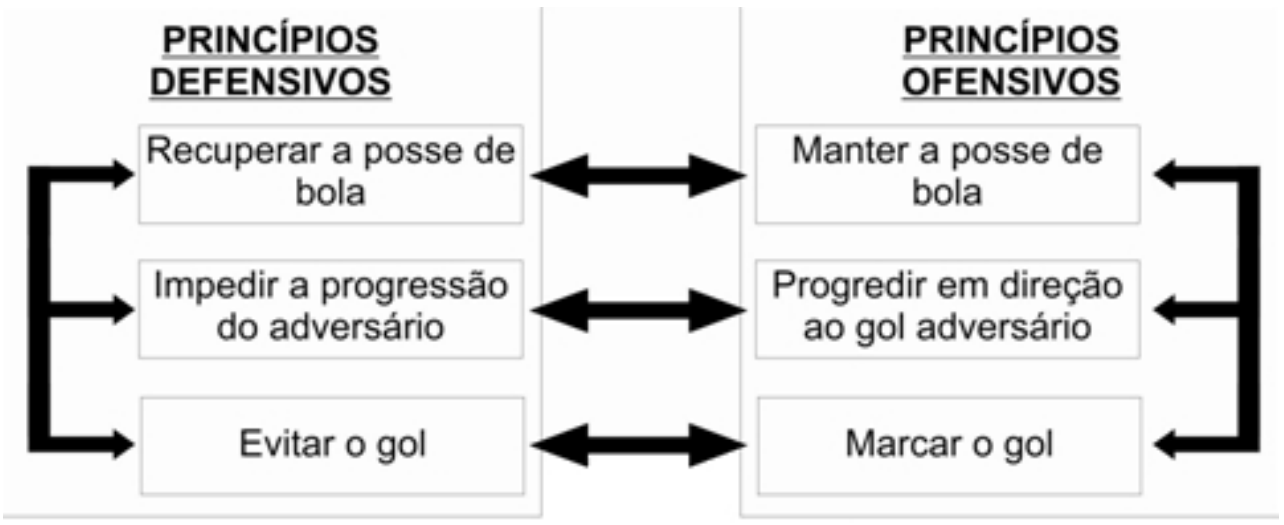

Figura 1 - Princípios operacionais defensivos e ofensivos. Fonte: adaptado de Bayer (1994).

\section{Discussões}

Alguns aspectos devem ser considerados quando nos referimos ao ensino dos sistemas defensivos do handebol para a categoria cadete. $\mathrm{O}$ 
primeiro deles refere-se ao desenvolvimento das capacidades físicas dos adolescentes. Machado e Barbanti (2007) afirmam que na adolescência ocorre um aumento acelerado das dimensões corporais, seja na altura do indivíduo, em seu peso ou mesmo nos comprimentos dos membros superiores e inferiores.

Para Gallahue e Ozmun (2003), as meninas apresentam o fim do crescimento do esqueleto por volta dos 16 anos, enquanto os meninos, nesta faixa etária, ainda apresentam crescimento da sua estrutura esquelética, o que nos fornece o indicativo de que há a possibilidade da coordenação dos movimentos ser prejudicada, tanto nos meninos como nas meninas. Tal afirmação nos remete à necessidade constante de exercícios, nessa fase do crescimento e desenvolvimento, que objetivem uma pluralidade de movimentos, como as variações de formas, de direções e de velocidades de deslocamentos e os diferentes posicionamentos do defensor em relação ao espaço que este se encontra na quadra ou em relação ao seu oponente direto.

Os autores supracitados apresentam, ainda, que na adolescência os ganhos de resistência e de força muscular ocorrem bruscamente nos meninos, enquanto nas meninas o pico dessas capacidades ocorre no início da puberdade, regredindo ligeiramente no final da adolescência (com aproximadamente 16 anos). Assim como a velocidade, a potência muscular das partes superiores e inferiores do tronco de meninos apresenta maiores progressos na adolescência; em contrapartida, as meninas apresentam, no mesmo período, estabilização ou queda das mesmas variáveis (GALLAHUE; OZMUN, 2003). Todas essas características vão ao encontro do estudo de Antón (1990), que sugere um incremento nos volumes e intensidades dos treinamentos físicos nessa categoria.

Bee (2003) afirma que na adolescência cada parte do corpo cresce em um ritmo diferente, imprimindo um aspecto assimétrico, o que muitas vezes transmite a ideia de que os adolescentes são descoordenados e, segundo a autora, não o são. Outro aspecto ressaltado pela autora é que, durante o período das operações formais (descrito na Teoria Cognitivo-Desenvolvimental de Piaget, segundo Dolle, 1978), o indivíduo busca resolver um problema de forma sistemática e metódica. Quando transcendemos esse conceito para o ensino do handebol, em específico dos sistemas defensivos, verificamos que uma determinada situação pode apresentar duas ou mais soluções possíveis, as quais devem ser apresentadas como alternativas pelo treinador ao con- 
junto de jogadores para que visualizem um número maior de possibilidades e as incorpore no seu repertório de ações.

O segundo aspecto refere-se aos métodos de ensino dos JCE's. Em termos gerais, o treinador poderá optar por centrar o ensino nas técnicas defensivas na repetitividade dos movimentos e, após o aprendizado desse conjunto de técnicas, tentar aproximá-los da orientação para o jogo. Esse modelo, segundo Costa e Nascimento (2004), apresenta a técnica como uma etapa de preparação, o que poderia dificultar o entendimento das situações de jogo e mesmo desmotivar alguns alunos devido ao exaustivo número de repetições do mesmo exercício (que tem como justificativa o domínio da técnica do movimento), apresentando-se como uma das possíveis consequências da adoção do modelo tecnicista.

Já o ensino centrado na tática tem como principal finalidade gerenciar a estrutura do jogo e as formas de intervenção dos jogadores dentro dos processos transitórios desse jogo, uma vez que os esportes coletivos "possuem características que não são totalmente previsíveis" (COSTA; NASCIMENTO, 2004, p. 51), o que se opõe à proposta tecnicista. Uma importante observação é a respeito da efetividade desse modelo de ensino, no qual o jogador pode possuir uma boa capacidade de tomada de decisão, porém o movimento executado não é eficaz para o objetivo proposto. Em contrapartida, há um alto nível motivacional dos alunos, devido ao jogo e às atividades lúdicas ocuparem um espaço central durante as aulas ou sessões de treinamentos.

A preocupação em encontrar um modelo de ensino dos JCE's que contemple os aspectos técnicos e táticos é apresentada por Greco (1998). O autor propõe uma metodologia centrada nas situações do jogo, ou em suas estruturas funcionais, que se inicia de situações simples, como a de um atacante e nenhum defensor - 1x0; a de um atacante e um coringa contra nenhum defensor $-1+1 \times 0$; a de um atacante e um coringa contra um defensor $-1+1$ x 1 e assim sucessivamente, passando por diversos níveis de variações, que se dão desde o número de jogadores e demais estruturas fixas da modalidade até alcançar a fase do jogo formal (6x6).

Dessa forma, é necessário que o treinador conheça alguns dos métodos de ensino dos JCE's para que, em diferentes momentos de uma mesma temporada, possa alternar momentos de ênfase da técnica ou da tática, lançando mão de ferramentas abordadas por uma ou outra metodologia. 
Ao assumir que a adolescência é uma fase de permanentes alterações nas capacidades físicas e nas características antropométricas, e que está repleta de desafios para os indivíduos, como o convívio social e a motivação em participar de uma equipe de esportes, um fator a ser ressaltado durante as sessões de treinamentos ou aulas é a resolução de situações-problemas de forma motivante. Essa resolução baseada em esquemas de estímulo-resposta deve abranger a importante tríplice de "tempo-espaço-situação", citada por Greco (2001), e não apenas a pressão de tempo e espaço. Nesse caso, prioriza-se a tomada de decisão correta para resolver as tarefas inerentes à situação apresentada, seja de cunho individual, coletivo ou simultâneo, ou seja, o "quando" e o "porquê" fazer e não apenas o "como" fazer, resultado de tarefas motoras descontextualizadas do jogo.

$\mathrm{O}$ terceiro aspecto relaciona-se com os conceitos das táticas defensivas individuais e coletivas. $\mathrm{O}$ entendimento de alguns conceitos torna-se necessário do ponto de vista metodológico, inclusive para a descrição do funcionamento dos sistemas defensivos, tais como:

- Dissuasão: ação de um defensor de deslocar-se na direção de um atacante sem a posse de bola, com o objetivo de impedir que este receba a bola;

- Báscula ou basculação: movimentos dos defensores em direção à circulação da bola, com o objetivo de cobrir grandes espaços gerados no sistema defensivo;

- Flutuação: deslocamento para frente que visa à aproximação do defensor em relação ao seu marcador direto, caso este esteja em posse da bola. Tem como objetivos reduzir o raio de ação do atacante com a posse da bola, retardar ou acelerar suas ações;

- Cobertura: movimento de um defensor na direção do espaço criado pela flutuação de um companheiro;

- Marcação: movimentos que visam impedir a aproximação dos atacantes em relação à meta a ser defendida; depende de rápidos deslocamentos e do contato corporal com o adversário;

- Bloqueio defensivo: movimento de colocar os braços e mãos na direção do arremesso para tentar impedir a passagem da bola para o gol.

Entendendo que a aprendizagem de uma modalidade envolve um processo de transmissão e apreensão de conhecimentos, preferencialmente de tarefas que os jogadores possam resolver para aquelas mais complexas, espera-se que, ao chegar à categoria cadete, esses jogadores devam ter vivenciado anteriormente, ou pelo menos possuir o conhecimento básico dos deslocamentos e posicionamentos adotados no 
handebol, principalmente se esses são oriundos da categoria infantil, o que nem sempre ocorre. Em todos os casos, a principal tarefa do treinador, além de atuar como mediador do processo de ensino-aprendizagem-treinamento que priorize a criação de situações-problema, será a de aumentar as possibilidades de intervenção desses jogadores e a de proporcionar um conhecimento mais aprofundado dos meios táticos defensivos, tanto na forma de executá-los como nos momentos corretos para as suas execuções, mesmo que anteriormente os jogadores não tenham vivenciado previamente o handebol e suas situações. Para Antón (2002), a variação do jogo ofensivo obriga o defensor a disporse de uma variabilidade de meios que permitam uma oposição com eficácia.

A participação simultânea em atividades de cunho técnico-tático durante a aula ou sessão de treinamento, que envolve jogadores iniciantes e experientes, pode proporcionar um ambiente propício para a aprendizagem de ambos. Para os iniciantes, tal experiência pode ser positiva quando se assume que o companheiro mais experiente seja um "apoio" ao aprendizado, ou um "modelo" a ser perseguido técnica e taticamente. Já para os mais experientes, a tentativa de auxiliar os iniciantes a encontrar a resolução das tarefas passa a ser uma forma "auxiliar" de colocar em questionamento o conteúdo de seu domínio, principalmente devido às observações realizadas pelos iniciantes e, por que não, pelos professores.

Sendo assim, baseia-se no fato de haver um aprendizado pela experiência vivenciada pelo jogador, a importância da realização de amistosos e jogos-treino com equipes mais experientes, preferencialmente da categoria imediatamente superior (juvenil), ou mesmo sessões esporádicas de treinamentos realizadas juntamente com jogadores da categoria adulta. Reforçando a ideia anterior, Antón (1990, p. 194) afirma que nesta etapa deve haver uma tentativa de "consolidar os hábitos técnico-táticos adquiridos iniciando o processo de especialização de forma simultânea", e sugere ainda que seja conveniente o jogador se desenvolver alternadamente em dois postos específicos. Assim sendo, a iniciação do processo de especialização refere-se à modalidade em questão e não exatamente aos postos específicos, havendo a necessidade de uma pluralidade de ensino conectada a um processo de especialização que pode ser facilitado por ambas as experiências adquiridas nas práticas citadas anteriormente (jogostreino e treinamentos com equipes mais experientes). 
Porém, há que ser feita a ressalva quanto à especialização dos jogadores na categoria cadete, na qual apenas aqueles jogadores que possuem experiência prévia na modalidade e bom desenvolvimento das capacidades de jogo passarão por esse processo de especialização. Não é o caso de grande parte dos jogadores que, por muitas vezes, tomam conhecimento da modalidade e de sua prática apenas nessa categoria.

\section{Considerações finais}

O trabalho na categoria cadete deve visar a pluralidade das situações de jogo e, como consequência, a formação de jogadores com amplos espectros de atuação, com boa capacidade de tomada de decisão baseada na percepção das ações ofensivas.

A diferença principal entre os sistemas defensivos de jogadores iniciantes e de atletas profissionais está nas características dos atacantes, como a diferença entre as intensidades das velocidades, a variabilidade das técnicas de intervenção, as interações táticas e a automatização de diferentes mecanismos. Trata-se dos mesmos sistemas em todas as idades, mas com problemas distintos a serem resolvidos, como as diferenças de velocidades e da melhor visualização, domínio e combinação de todas as disponibilidades de desencadeamentos das ações ofensivas e defensivas, que exigem diferentes formas de interação.

Tarefas simples, como jogos em igualdades numéricas em espaços reduzidos ou superioridades numéricas defensivas $(2 \times 3,5 \times 6 \ldots)$, e tarefas complexas, como inferioridades numéricas defensivas $(2 \times 1$, $3 \times 2 . .$.$) ou mesmo desequilíbrios momentâneos defensivos, como um$ defensor sendo introduzido após o início da situação ofensiva, devem ser inseridos constantemente nas aulas e nas sessões de treinamentos. Tais tarefas possuem, em muitos casos, múltiplas soluções que devem ser buscadas pelos jogadores.

Mas, para cumprir seu principal objetivo enquanto sistema defensivo, duas premissas devem ser respeitadas: o comportamento tático individual e as ajudas mútuas entre os defensores. Necessariamente durante o processo de ensino-aprendizagem-treinamento (EAT) atividades de cunhos individual e coletivo devem ser estimuladas, desde a iniciação ao handebol até o treinamento em equipes de alto nível de rendimento. 
No handebol nos deparamos com estruturas que não se alteram (ou estruturas fixas) e também com estruturas que variam no decorrer do jogo (ou estruturas variáveis), que são: a) estruturas fixas: a quadra, o tempo, o gol e a bola; e b) estruturas variáveis: o número de jogadores, os sistemas ofensivos e defensivos, as formas de utilização dos fundamentos, a interação entre os jogadores e as sanções da arbitragem. Todos esses "componentes estruturais" da modalidade devem ser considerados e utilizados como ferramentas para a variação dos estímulos durante as sessões de treinamentos.

Dessa forma, o treinador pode optar, por exemplo, pela redução ou ampliação do espaço de jogo; pela variação do número de jogadores na relação ataque x defesa; pela alternância entre os tipos de sistemas defensivos ou condutas individuais dos defensores; pela maior pressão na relação do tempo de jogo; ou mesmo combinando algumas dessas variáveis. Essas variações podem ocorrer em diferentes momentos do treinamento, como nas atividades de caráter lúdico, nas situações reduzidas de jogo ou mesmo durante a realização do jogo formal.

The system of defensive teaching of handball: methodological considerations on cadet category

\begin{abstract}
In cadet category, teaching defensive system must prioritize the resolution of either motor or cognitive tasks, considering the development of the players, the teaching methods adopted by coaches and previous experiences of players within the modality. Identifying these features allows pointing out the need of a formation of offensive defenders, disturbing constantly the oponents, limiting their actin areas and complicating the offensive collective game, for a quick recovery of posession of the ball. The coach's job must be based on formation of players with plural performance and flexible behaviour in the game, and not expert technical and tactically players.
\end{abstract}

Keywords: Handball - Pedagogy of Sport -Defensive Tactics

La enseñanza de los sistemas defensivos del balonmano: consideraciones metodológicas en la categoría cadete

\title{
Resumen
}

En la categoría cadete la enseñanza de los sistemas defensivos debe priorizar la resolución de variadas tareas, motrices o cognitivas, considerando los niveles de desenvolvimiento de los jugadores, los métodos de enseñanza adoptados por los entrenadores y las experiencias anteriores de los jugadores en la modalidad. La identificación de esas características permite apuntar la necesidad de formación de defensores ofensivos, que perturben los atacantes adversarios, limitando sus áreas 
de actuación y dificultando el juego colectivo ofensivo, para que haya la rápida recuperación de la posesión del balón. El trabajo del entrenador debe ser el de formar jugadores con pluralidad del actuación y del comportamiento flexible en el juego, y no de jugadores especializados técnico-tácticamente.

Palabras clave: Balonmano - Pedagogía del Deporte - Táctica Defensiva

\section{Referências}

ANTÓN, J. L. Balonmano: fundamentos y etapas de aprendizaje. Madrid: Gymnos Editorial, 1990.

Balonman: táctica grupal defensiva - concepto, estructura y metodología. Granada: Grupo Editorial Universitário, 2002.

BAYER, C. O ensino dos desportos colectivos. Lisboa: Dinalivros, 1994.

BEE, H. A criança em desenvolvimento. 9. ed. Porto Alegre: Artmed, 2003.

COSTA, L. C. A. da; NASCIMENTO, J. V. do. O ensino da técnica e da tática: novas abordagens metodológicas. Revista da Educação Física/Universidade Estadual de Maringá, v. 15, n. 2, p. 49-56, 2004.

DOLLE, J. M. Para compreender Jean Piaget. Rio de Janeiro: Zahar, 1978.

EHRET, A. et al. Manual de handebol: treinamento de base para crianças e adolescentes. 1. ed. São Paulo: Phorte, 2002.

GALLAHUE, D.; OZMUN, J. Compreendendo o desenvolvimento motor: bebês, crianças, adolescentes e adultos. 2. ed. São Paulo: Phorte Editora, 2003.

GARGANTA, J. O ensino dos jogos desportivos. 2. ed. Porto: Centro de Estudos dos Jogos Desportivos, Universidade do Porto, 1995.

GRECO, P. J. Iniciação esportiva universal: metodologia da iniciação esportiva na escola e no clube. Belo Horizonte: Ed. UFMG, 1998.

Métodos de ensino-aprendizagem-treinamento nos jogos esportivos coletivos. In: GARCIA, E. S.; LEMOS, K. L. M. (org.), Temas atuais VI em Educação Física e Esportes, Belo Horizonte: 
Health, 2001. p. 48-72.

HERRERO, J. A. G. Entrenamiento en balonmano: bases para la construcción de un proyecto de formación defensiva. Barcelona: Editorial Paidotribo, 2003.

MACHADO, D. R. L.; BARBANTI, V. J. Maturação esquelética e crescimento em crianças e adolescentes. Revista Brasileira de Cineantropometria e Desempenho Humano, v. 9, n. 1, p. 12-20, 2007.

MEDINA, A. A.; ORTÍN, N. U. Guía didáctica de balonmano. Murcia: Librero Editor, 2002.

MOREIRA, I.; TAVARES, F. Configuração do processo ofensivo no jogo de andebol pela relação cooperação/oposição relativa à zona da bola. Estudo em equipas portuguesas de diferentes níveis competitivos. Revista Portuguesa de Ciências do Desporto, v. 4, n. 1, p. 2938, 2004.

RÉ, A. H. N. et al. Relações entre crescimento, desempenho motor, maturação biológica e idade cronológica em jovens do sexo masculino. Revista Brasileira de Educação Física e Esportes, São Paulo, v. 19, n. 2, p. 153-162, 2005.

REIS, H. H. B. dos. O ensino dos jogos coletivos esportivizados na escola. 1994. 75f. Dissertação (Mestrado em Educação Física) - Centro de Educação Física e Desporto, Universidade Federal de Santa Maria, Santa Maria, 1994.

SIMÕES, A. C. Handebol defensivo: conceitos técnicos e táticos. 2. ed. São Paulo: Phorte Editora, 2002.

Recebido em: 09/09/2009

Revisado em: 10/11/2009

Aprovado em: 20/11/2009

Endereço para correspondência

rafael.pombo@yahoo.com.br

Rafael Pombo Menezes

Centro Universitário Nossa Senhora do Patrocínio, Educação Física.

R. Madre Maria Basília, 965 - Centro

13300-000 - Itu, SP - Brasil

Pensar a Prática, Goiânia, v. 13, n. 1, p. 1-15, jan./abr. 2010 